\title{
Урожайность и качество клубней нового сорта картофеля Кумач в зависимости от комплекса агроприемов
}

\author{
Yield and quality of new potato variety Kumach depending on set of agricultural practices
}

Киселев А.И., Шабанов А.Э.

\section{Аннотация}

Исследования проводили на экспериментальной базе «Коренево» ВНИИКХ (Московская область) в 2018-2019 годах на новом среднеспелом сорте картофеля Кумач. В опыте на дерново-подзолистой супесчаной почве изучали агротехнические приемы (сроки, густоту посадки и способы внесения минеральных удобрений) с целью: ускорить рост, развитие растений и формирование хозяйственно значимого урожая клубней до наступления неблагоприятных метеорологических условий (жара, засуха); улучшить параметры товарных клубней в структуре урожая; обеспечить бесперебойное питание растений в течение всей вегетации. Клубни высаживали в два срока: ранний (третья декада апреля при температуре почвы не ниже $5^{\circ} \mathrm{C}$ ) и базовый (контроль) - через 7-10 дней после первого срока. Посадку проводили на фоне удобрений, внесенных локально тремя способами при нарезке гребней и последующих междурядных обработках: 1. единовременно $\mathrm{N}_{90} \mathrm{P}_{90} \mathrm{~K}_{135}$ (контроль); 2. дробно (стартовое $\mathrm{N}_{60} \mathrm{P}_{60} \mathrm{~K}_{90}+$ подкормка $\mathrm{N}_{30} \mathrm{P}_{30} \mathrm{~K}_{45}$ через 7-10 дней после всходов); 3. дробно (стартовое $\mathrm{N}_{30} \mathrm{P}_{30} \mathrm{~K}_{45}+$ подкормка $\mathrm{N}_{30} \mathrm{P}_{30} \mathrm{~K}_{45}$ через 7-10 дней после всходов + подкормка $\mathrm{N}_{30} \mathrm{P}_{30} \mathrm{~K}_{45}$ в фазу бутонизации). Густота посадки: 44 (контроль); 50 и 56 тыс. клубней/га по схеме $75 \times 30 ; 75 \times 27$ и $75 \times 24$ см. Ранняя посадка способствовала ускорению появления всходов на 4-6, а фазы бутонизации и цветения растений на 3-7 дней. На варианте с посадкой клубней в 1 срок и дробным внесением удобрений (стартовое $\mathrm{N}_{60} \mathrm{P}_{60} \mathrm{~K}_{90}$ + подкормка $\mathrm{N} \mathrm{N}_{30} \mathrm{P}_{30} \mathrm{~K}_{45}$ через 7-10 дней после всходов) увеличивались масса ботвы, площадь ассимиляционной поверхности листьев в среднем на 2,2 т/га и 4,6 тыс. м²/га, а при загущении посадок - на 1,3-3,8 т/га и 1,4-4,5 тыс. м²/га в сравнении с контрольными вариантами. Прибавка урожая от ранней посадки составила в среднем за два года до 1,8 т/га или 5,1\%; от дробного внесения удобрений до 2,5 т/га или $7,1 \%$, а от загущения посадок - на 1,9-2,9 т/га или до 8,2\% в сравнении с соответствующими контролями. Совокупное применение агроприемов в опыте позволило получить прибавку урожая в размере 4,0 т/га или $11,4 \%$ в сравнении с базовыми вариантами. Условный доход составил 41 тыс. р/га.

Ключевые слова: урожайность, срок, густота посадки, способ внесения, показатели качества клубней, условный доход.

Для цитирования: Киселев А.И., Шабанов А.Э. Урожайность и качество клубней нового сорта картофеля Кумач в зависимости от комплекса агроприемов // Картофель и овощи. 2020. №4. С. 29-32. https://doi.org/10.25630/PAV.2020.75.83.005

\author{
Kiselev A.I., Shabanov A.E.
}

\section{Abstract}

The research of new medium-ripe potato variety Kumach was conducted at the experimental base "Korenevo» (Lorch Potato Research Institute, Moscow region) in 2018-2019 years. In the experiment on sod-podzolic sandy loam soil, agricultural techniques (timing, planting density and methods of mineral fertilizers applying) were studied with the aim of: 1 . accelerate the growth, development of plants and the achievement of high yield before the beginning of unfavorable conditions (heat, drought); 2. improve the parameters of tubers commodity in the crop structure; 3 . ensure plant nutrition throughout the growing season on constant level. Tubers were planted in 2 terms: early (3rd decade of April at a soil temperature above $+5^{\circ} \mathrm{C}$ ) and basic (control) - 7-10 days after the first term. Planting was carried out on the background of fertilizers applied locally during ridging in three variants: 1. $\mathrm{N}_{90} \mathrm{P}_{90} \mathrm{~K}_{135}$ (control) at a time; 2. fractional (starting $\mathrm{N}_{60} \mathrm{P}_{60} \mathrm{~K}_{90}$ + top dressing $\mathrm{N}_{30} \mathrm{P}_{30} \mathrm{~K}_{45}$ ) 7-10 days after germination; 3 . fractional (starting $\mathrm{N}_{30} \mathrm{P}_{30} \mathrm{~K}_{45}+$ top dressing $\mathrm{N}_{30} \mathrm{P}_{30} \mathrm{~K}_{45}$ 7-10 days after germination + top dressing $\mathrm{N}_{30} \mathrm{P}_{30} \mathrm{~K}_{45}$ in the budding phase). Planting density: 44 (control); 50 and 56 thousand tubers/ha according to the scheme $75 \times 30 ; 75 \times 27$ and $75 \times 24 \mathrm{~cm}$. Early planting contributed to acceleration of seedlings emergence by 4-6 days, and the phases of budding and flowering of plants by 3-7 days. In variant of planting tubers in first term (fractional appliance $-\mathrm{N}_{60} \mathrm{P}_{60} \mathrm{~K}_{90}$ by ridging $+\mathrm{N}_{30} \mathrm{P}_{30} \mathrm{~K}_{45}$ after 7-10 days after germination) the mass of the plants, the area of the assimilation surface of the leaves increased by an average on $2.2 \mathrm{t} / \mathrm{ha}$ and 4.6 thousand $\mathrm{m}^{2} /$ ha, and in variant of thickening the plantings-by 1.3-3.8 t/ha and 1.44.5 thousand $\mathrm{m}^{2} /$ ha in comparison with the control variants. The increase in yield from early planting was on average up to $1.8 \mathrm{t} / \mathrm{ha}$ or $5.1 \%$ over 2 years; from fractional fertilization up to $2.5 \mathrm{t} /$ ha or $7.1 \%$, and from thickening of plantings-by $1.9-2.9 \mathrm{t} /$ ha or up to $8.2 \%$ in comparison with the corresponding controls. The combined use of agricultural practices in the experiment allowed to get an increase in yield of $4.0 \mathrm{t} / \mathrm{ha}$ or $11.4 \%$ in comparison with the control variants. Income was 41 thousand rubles / ha.

Key words: yield, term and density of planting, method of application, quality indicators of tubers, income.

For citing: Kiselev A.I., Shabanov A.E. Yield and quality of new potato variety Kumach depending on set of agricultural practices. Potato and vegetables. 2020. No4. Pp. 29-32. https://doi.org/10.25630/ PAV.2020.75.83.005 (In Russ.) оздание нового, высокопродуктивного сорта это еще не решение проблемы повышения урожайности. Потенциальные возможности генотипа смогут проявиться лишь в том случае, если после предварительного изучения для него агротехнически будут созданы условия в максимальной степени отвечающие требованиям сорта [1].

В комплексе агротехнических мероприятий по созданию оптимальных условий выращивания и получению высоких и стабильных урожаев картофеля важное значение имеют срок, густота посадки, удобрения, полив и многие другие факторы. Один из эффективных агроприемов, повышающий урожайность и качество картофеля без дополнительных материальных затрат,- правильно выбранный срок посадки с учетом биологических особенностей возделываемого сорта, качества семенного материала, гранулометрического состава, температуры почвы и т.д. [2, 3]. Другой элемент 
агротехники, который серьезно влияет на продуктивность и качество клубней - научно обоснованная и рациональная густота посадки клубней [4, 5]. При установлении ее оптимальной величины, как правило, также учитывают биологические особенности сорта, цели выращивания продукции в конкретных почвенно-климатических условиях и ее необходимо рассматривать в неразрывной связи с другими агроприемами [6, 7].

Влияние упомянутых выше факторов в отдельности на урожайность, показатели качества и т.д., достаточно известно. Однако данных об эффективности их применения в комплексе в зависимости от биологических особенностей сортов, особенно новых, и почвенно-климатических условий выращивания недостаточно. В связи с этим в 2018-2019 годы мы изучали отзывчивость среднеспелого сорта картофеля Кумач (рис.) селекции ВНИИКХ на раздельное и совместное применение таких агротехнических приемов, как срок, густота посадки, способ внесения удобрений.

Цель исследований: оценить влияние способов внесения удобрений, срока посадки, густоты посадки на урожайность и качество картофеля сорта Кумач. Задачи исследований: ускорить рост, развитие растений и формирование хозяйственно значимого урожая клубней до наступления неблагоприятных метеорологических условий (жара, засуха); улучшить параметры товарных клубней в структуре урожая; обеспечить бесперебойное питание растений в течение всей вегетации, так как во время выпадения осадков, особенно на супесчаных почвах, происходит вымывание питательных веществ из корнеобитаемого слоя.

Условия, материалы и методы исследований

Опыты проводили на экспериментальной базе «Коренево» ВНИИКХ (Московская область) на дерново-подзолистой супесчаной почве с низким содержанием гумуса (1,8-1,9\%), высоким - подвижного фосфора (269-278) и ниже среднего - обменного калия (128-130) мг/кг почвы. Минеральные удобрения (азофоска с добавлением калимагнезии) вносили локально двумя лентами культиватором КРН-4,2 с туковысевающими аппаратами в середине апреля. Изучали три способа внесения: 1. основное $\mathrm{N}_{90} \mathrm{P}_{90} \mathrm{~K}_{135}$ (контроль) при нарезке гребней; 2. дробное (стартовое $\mathrm{N}_{60} \mathrm{P}_{60} \mathrm{~K}_{90}+$ подкормка $\mathrm{N}_{30} \mathrm{P}_{30} \mathrm{~K}_{45}$ ) через 7-10 дней после всходов; 3. дробное (стартовое $\mathrm{N}_{30} \mathrm{P}_{30} \mathrm{~K}_{45}+$ подкормка $\mathrm{N}_{30} \mathrm{P}_{30} \mathrm{~K}_{45}$ через 7-10 дней после всходов + подкормка $\mathrm{N}_{30} \mathrm{P}_{30} \mathrm{~K}_{45}$ в фазу бутонизации).

Высаживали картофель в два срока: ранний (третья декада апреля при температуре почвы не ниже $5{ }^{\circ} \mathrm{C}$ ) и базовый (контроль) - через 7-10 дней после первого срока. Клубни массой 50-80 г высаживали клоновой сажалкой $\mathrm{CH}-4 Б-К$ на глубину 8-10 см.

Исследовали три густоты посадки: 44 (контроль); 50 и 56 тыс. клубней/га по схеме 75×30; 75×27 и $75 \times 24$ см. Посадку проводили во второй срок и внесении удобрений в дозе $\mathrm{N}_{90} \mathrm{P}_{90} \mathrm{~K}_{135}$

Повторность в опыте трехкратная, площадь делянки - $30 \mathrm{~m}^{2}$. Метеорологические условия вегетационных периодов в годы проведения исследований различались, что повлияло на рост, развитие, продуктивность растений и показатели качества клубней. Май 2018 года был теплее на $3,4{ }^{\circ} \mathrm{C}$, а осадков выпало в пределах нормы. В июне во второй половине месяца установилась жаркая и очень сухая погода. Осадков выпало в 2 раза меньше нормы. Июль был жарким и влажным. Температура воздуха составила $20,4{ }^{\circ} \mathrm{C}$ при норме 19,3 ${ }^{\circ} \mathrm{C}$. Осадков выпало 87,2 мм (норма 79,3 мм). Август был жарким и сухим. Температура на $2,6^{\circ} \mathrm{C}$ выше, а осадков выпало в два раза меньше нормы. ГТК2018 = 0,89 (засушливый).

Вегетационный период 2019 года характеризовался неравномерным выпадением осадков. Засуха в июне сменилась избыточным увлажнением и похолоданием в июле. Температура была на $2,4{ }^{\circ} \mathrm{C}$ ниже, а осадков выпало в 1,5 раза больше нормы. Погода в августе была теплая и влажная.

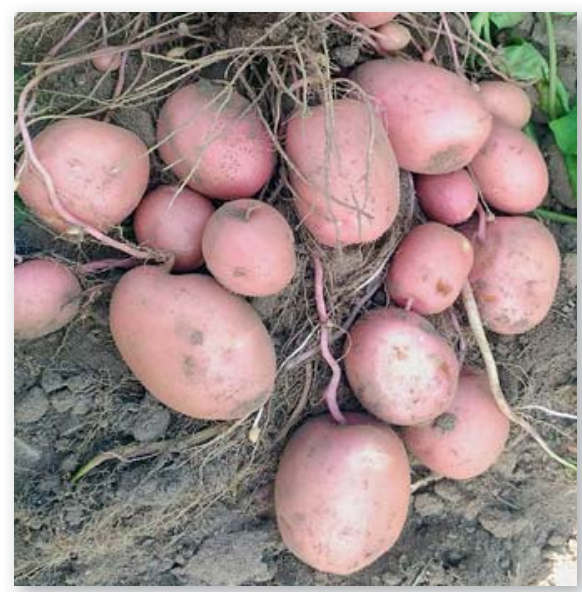

Клубни сорта Кумач (6 июля)

Температура воздуха и количество выпавших осадков были близки к норме. ГТК2019 = 1,39 (влажный).

Фенологические наблюдения, определение биометрических показателей растений, качества клубней, экономических параметров выращивания, статистическая обработка данных урожайности - по общепринятым методикам [8-12].

\section{Результаты исследований}

Сроки наступления и продолжительность фаз развития растений картофеля в опыте зависели от срока посадки и метеорологических условий вегетационного периода. Наблюдения показали, что при ранней посадке всходы появлялись на 4-6 дней, а бутонизация и цветение наступали на 3-7 дней раньше в сравнении с контролем. Высота растений, количество стеблей и число клубней в кусте были в опыте примерно одинаковыми. Большие значения по массе ботвы и площади листовой поверхности рас-

Таблица 1. Урожайность клубней в зависимости от срока посадки и способа внесения минеральных удобрений, 2018-2019 годы

\begin{tabular}{|c|c|c|c|c|c|}
\hline \multirow[b]{2}{*}{ Способ внесения удобрений } & \multicolumn{3}{|c|}{ Урожайность по годам, т/га } & \multicolumn{2}{|c|}{ \pm от } \\
\hline & 2018 & 2019 & средняя & $\begin{array}{c}\text { срока } \\
\text { посадки }\end{array}$ & $\begin{array}{c}\text { способа } \\
\text { внесения }\end{array}$ \\
\hline
\end{tabular}

Первый срок посадки: 27 апреля

\begin{tabular}{|l|l|l|l|l|r|}
\hline Основное $-\mathrm{N}_{90} \mathrm{P}_{90} \mathrm{~K}_{135}$ (контроль) & 29,0 & 44,9 & 37,0 & $+1,8$ & - \\
\hline Дробное: $\mathrm{N}_{60} \mathrm{P}_{60} \mathrm{~K}_{90}+\mathrm{N}_{30} \mathrm{P}_{30} \mathrm{~K}_{45}$ & 30,8 & 47,5 & 39,2 & $+1,5$ & $+2,2$ \\
\hline Дробное: $\mathrm{N}_{30} \mathrm{P}_{30} \mathrm{~K}_{45}+\mathrm{N}_{30} \mathrm{P}_{30} \mathrm{~K}_{45}{ }^{+}$ & 27,3 & 43,3 & 35,3 & $+1,5$ & $-1,7$ \\
\hline $\mathrm{N}_{30} \mathrm{P}_{30} \mathrm{~K}_{45}$ &
\end{tabular}

Первый срок посадки: 4-6 мая (контроль)

Основное: $\mathrm{N}_{90} \mathrm{P}_{90} \mathrm{~K}_{135}$ (контроль)

Дробное: $\mathrm{N}_{60} \mathrm{P}_{60} \mathrm{~K}_{90}+\mathrm{N}_{30} \mathrm{P}_{30} \mathrm{~K}_{45}$

Дробное: $\mathrm{N}_{30} \mathrm{P}_{30} \mathrm{~K}_{45}+\mathrm{N}_{30} \mathrm{P}_{30} \mathrm{~K}_{45}+$

$\mathrm{N}_{30} \mathrm{P}_{30} \mathrm{~K}_{45}$

$\mathrm{HCP}_{05}$

Влияние факторов, \%

\begin{tabular}{|c|c|c|c|c|}
\hline 27,5 & 42,9 & 35,2 & - & - \\
\hline 29,4 & 46,0 & 37,7 & - & $+2,5$ \\
\hline 25,5 & 42,0 & 33,8 & - & $-1,4$ \\
\hline 1,1 & 1,8 & - & - & - \\
\hline- & - & - & 17 & 71 \\
\hline
\end{tabular}


Таблица 2. Урожайность клубней в зависимости от густоты посадки, 2018-2019 годы

\begin{tabular}{|l|c|}
\hline $\begin{array}{c}\text { Густота посадки, } \\
\text { тыс. шт/га }\end{array}$ & Схема посадки, см \\
\hline 44 (контроль) & $75 \times 30$ \\
\hline 50 & $75 \times 27$ \\
\hline 56 & $75 \times 24$ \\
\hline HCР $_{05}$ & - \\
\hline
\end{tabular}

тений отмечены на варианте с ранней посадкой + дробное внесение удобрений (стартовое $\mathrm{N}_{60} \mathrm{P}_{60} \mathrm{~K}_{90}+$ подкормка $\left.\mathrm{N}_{30} \mathrm{P}_{30} \mathrm{~K}_{45}\right)$ через 7-10 дней после всходов в среднем на 2,2 т/га и 4,6

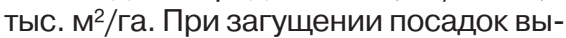
сота растений была в среднем на 4 см выше, а масса ботвы и площадь листьев больше на 1,3-3,8 т/га и 1,4-4,5 тыс. $\mathrm{M}^{2} /$ га, соответственно, в сравнении с контролем. Наибольшие значения биометрических показателей растений отмечены в относительно благоприятных для картофеля метеоусловиях 2019 года, что, в конечном итоге предопределило уровень урожайности сорта. Результаты исследований, представленные в таблице 1, свидетельствуют о различной степени влияния изучаемых агроприемов на урожайность сорта.

Установлено, что при посадке клубней в первый срок (ранний) урожайность увеличивалась в среднем за два года на 1,5-1,8 т/га или до $5,1 \%$ в сравнении с контролем. Это, по нашему мнению, связано с лучшим развитием растений, удлинением периода вегетации и накопления урожая в этих вариантах на8-

\begin{tabular}{|c|}
\hline $\begin{array}{c}\text { Плотность стеблестоя, } \\
\text { тыс. шт/га }\end{array}$ \\
167 \\
210 \\
219 \\
\hline
\end{tabular}

\begin{tabular}{|c|c|}
\hline \multicolumn{2}{|c|}{ Урожайность по го } \\
\hline 2018 & 2019 \\
\hline 27,5 & 42,9 \\
\hline 29,8 & 44,3 \\
\hline 30,8 & 45,4 \\
\hline 1,2 & 1,5 \\
\hline
\end{tabular}

10 дней. Статистическая обработка данных урожайности показала, что влияние срока посадки в целом составило $14 \%$ от действия всех факторов в опыте.

При оценке способов внесения удобрений наиболее эффективным оказался вариант с дробным применением (стартовое $\mathrm{N}_{60} \mathrm{P}_{60} \mathrm{~K}_{90}$ ) при нарезке гребней + (подкормка $\left.\mathrm{N}_{30} \mathrm{P}_{30} \mathrm{~K}_{45}\right)$ при междурядной обработке через 7-10 дней после всходов. Прибавка урожая в среднем за два года составила 2,2-2,5 т/га или до 7,1\% в сравнении с контролем. Влияние этого способа на урожайность составило $71 \%$ от действия всех факторов в опыте.

Ранняя посадка клубней на фоне дробного внесения удобрений обеспечила получение прибавки урожая в размере 4,0 т/га или $11,4 \%$ в сравнении с контролем (посадка во второй срок $+\mathrm{N}_{90} \mathrm{P}_{90} \mathrm{~K}_{135}$ ).

Загущение посадок до 50 и 56 тыс. клубней/га способствовало достоверному увеличению урожайности в среднем за два года на 1,9-2,9 т/га или до 2,8\% в сравнении с контролем (табл. 2).

\begin{tabular}{|c|c|c|}
\hline дам, т/га & \multicolumn{2}{|c|}{ \pm к контролю } \\
\hline средняя & т/га & $\%$ \\
\hline 35,2 & - & - \\
\hline 37,1 & $+1,9$ & 5,4 \\
\hline 38,1 & $+2,9$ & 8,2 \\
\hline- & - & - \\
\hline
\end{tabular}

Это, обусловлено увеличением плотности стеблестоя в этих вариантах со 167 до 210-219 тыс. шт/ га и достаточной увлажненностью почвы. Подтверждением этого могут быть сложившиеся метеоусловия 2019 года, когда умеренная температура воздуха и высокая влажность почвы в июле - начале августа положительно влияли на уровень урожайности сорта. В 2018 году она составила в среднем по вариантам опыта 29,4, а в 2019 г - 44,2 т/га. Разница составила 14,8 т/га, что свидетельствует о высокой степени влияния метеоусловий вегетационного периода на урожайность картофеля.

Данные, представленные в таблице 3, показывают, что в варианте с ранней посадкой и дробном внесении удобрений (стартовое $\mathrm{N}_{60} \mathrm{P}_{60} \mathrm{~K}_{90}+$ подкормка $\mathrm{N}_{30} \mathrm{P}_{30} \mathrm{~K}_{45}$ ) через 7-10 дней после всходов товарность клубней была на 1\% выше, чем в контроле.

По содержанию крахмала, сухого вещества, витамина С, белка и редуцирующих сахаров в клубнях существенных различий не выявлено. Концентрация нитратов в клубнях была практически одинаковой

Таблица 3. Показатели качества клубней в зависимости от срока посадки и способа внесения минеральных удобрений, среднее 2018-2019 годы

\begin{tabular}{|c|c|c|c|c|c|c|c|c|c|}
\hline \multirow{2}{*}{\multicolumn{3}{|c|}{ Способ внесения удобрений }} & \multirow{2}{*}{\multicolumn{2}{|c|}{ Товарность, }} & \multicolumn{5}{|c|}{ Содержание } \\
\hline & & & & & крахмала, \% & $\begin{array}{l}\text { нитратов, } \\
\text { мг/кг }\end{array}$ & $\begin{array}{c}\text { витамина C, } \\
\text { мг } / \%\end{array}$ & \multirow[t]{2}{*}{ белка, \% } & $\begin{array}{c}\text { редуцирующих } \\
\text { сахаров, \% }\end{array}$ \\
\hline \multicolumn{9}{|c|}{ Первый срок посадки - 27 апреля } & \\
\hline \multicolumn{3}{|c|}{ Основное: $\mathrm{N}_{90} \mathrm{P}_{90} \mathrm{~K}_{135}$ (контроль) } & \multicolumn{2}{|c|}{88} & 11,8 & 151 & 14,3 & 0,8 & 1,18 \\
\hline \multicolumn{3}{|c|}{ Дробное: $\mathrm{N}_{60} \mathrm{P}_{60} \mathrm{~K}_{90}+\mathrm{N}_{30} \mathrm{P}_{30} \mathrm{~K}_{45}$} & \multicolumn{2}{|c|}{88} & 11,8 & 162 & 15,4 & 1,0 & 1,23 \\
\hline \multicolumn{3}{|c|}{ Дробное: $\mathrm{N}_{30} \mathrm{P}_{30} \mathrm{~K}_{45}+\mathrm{N}_{30} \mathrm{P}_{30} \mathrm{~K}_{45}+\mathrm{N}_{30} \mathrm{P}_{30} \mathrm{~K}_{45}$} & \multicolumn{2}{|c|}{86} & 11,4 & 183 & 14,3 & 0,9 & 1,16 \\
\hline \multicolumn{10}{|c|}{ 2-й срок посадки - 4-6 мая (контроль) } \\
\hline \multicolumn{3}{|c|}{ Основное: $\mathrm{N}_{90} \mathrm{P}_{90} \mathrm{~K}_{135}$ (контроль) } & \multicolumn{2}{|c|}{87} & 11,7 & 161 & 15,6 & 0,9 & 1,18 \\
\hline Дробное: $\mathrm{N}_{60} \mathrm{P}_{60} \mathrm{~K}_{90}$ & $+\mathrm{N}_{30} \mathrm{P}_{30} \mathrm{~K}_{45}$ & & & & 11,7 & 171 & 17,1 & 0,9 & 1,20 \\
\hline Дробное: $\mathrm{N}_{30} \mathrm{P}_{30} \mathrm{~K}_{45}$ & $+\mathrm{N}_{30} \mathrm{P}_{30} \mathrm{~K}_{45}+\mathrm{N}_{30}$ & ${ }_{30} \mathrm{~K}_{45}$ & & & 11,5 & 186 & 15,4 & 0,8 & 1,26 \\
\hline Таблица 4. Показ & тели качеств & убне & й в & MOC & от густоты по & дки, среднее & 2018-2019 год & & \\
\hline & & Macc & са то & ого к & уубня по годам & & Cor & әржание & \\
\hline тыс. шт/га & $\%$ & 201 & 18 & 201 & средня & крахмала, & $\begin{array}{c}\text { витамин C, } \\
\text { мг/\% }\end{array}$ & белка, \% & $\begin{array}{c}\text { редуцирующих } \\
\text { сахаров, \% }\end{array}$ \\
\hline 44 (контроль) & 87 & 10 & 03 & 115 & 111 & 11,5 & 15,6 & 0,9 & 1,18 \\
\hline 50 & 85 & 96 & 6 & $10 s$ & 103 & 12,3 & 16,5 & 1,0 & 1,19 \\
\hline 56 & 83 & 86 & 6 & 105 & 96 & 12,2 & 16,6 & 0,9 & 1,28 \\
\hline
\end{tabular}


в вариантах и не превышала ПДК Столовые качества клубней не зависели от исследуемых агроприемов. Клубни имели хороший вкус, слаборазваристые, не темнеющие при варке, пригодны для приготовления пюре, жарки и запекания. Сорт относится к кулинарному типу АВ.

При загущении посадок отмечено снижение товарности урожая на 2-4\% и уменьшение средней массы одного товарного клубня со 111 до 103-96 г (табл. 4).

Это важно, так как в структуре урожая в контрольном варианте формируются отдельные чрезмерно крупные клубни, не пользующиеся спросом у покупателя.

Содержание крахмала в клубнях увеличивалось на 0,8\%, а витамина С на 1,0 мг/\% в сравнении с контролем. Существенных различий по на- коплению белка и редуцирующих сахаров в клубнях по вариантам опыта не выявлено.

При определении экономической эффективности возделывания сорта учитывали все затраты, связанные с производством картофеля, а так же дополнительные средства при увеличении нормы посадочного материала. Товарный урожай оценивали по 10, а нестандартный картофель по 3 $\mathrm{p} / \mathrm{Kг}$.

Расчеты свидетельствуют, что на вариантах опыта с ранней посадкой клубней условный доход в среднем за два года достигал 18, а с дробнолокальным внесением дозы $\mathrm{N}_{60} \mathrm{P}_{60} \mathrm{~K}_{90}$ при нарезке гребней + подкормка $\mathrm{N}_{30} \mathrm{P}_{30} \mathrm{~K}_{45}$ при междурядной обработке через 7-10 дней после всходов до 26 тыс. р/га. При совместном их применении условный доход составил
41 тыс. р/га в сравнении с контролем. Себестоимость урожая снижалась на 0,3 р/кг.

При загущении посадок до 50 тыс. клубней/га условный доход увеличивался на 4 тыс. р/га в сравнении с контролем.

\section{Выводы}

Таким образом, комплекс агротехнических приемов, включающий раннюю посадку (третья декада апреля при температуре почвы не ниже $5^{\circ} \mathrm{C}$ ) клубней с густотой 50 тыс. клубней/га на фоне дробно-локального внесения удобрений (стартовое $\left.\mathrm{N}_{60} \mathrm{P}_{60} \mathrm{~K}_{90}\right)$ при нарезке гребней + (подкормка $\mathrm{N}_{30} \mathrm{P}_{30} \mathrm{~K}_{45}$ ) при междурядной обработке через 7-10 дней после всходов обеспечивает получение гарантированного урожая с высокими экономическими показателями.

\section{References}

1.Жученко А.А. Пути всесторонней интенсификации растениеводства // Будущее науки: Международный ежегодник. М.: Знание, 1984. Вып. 17. С. 168-176.

2.Будин К.З. За высокий урожай картофеля. Л.: Знание, 1981. $36 \mathrm{c.}$

3.Дмитриева 3.А. Оптимальные сроки посадки // Картофель и овощи. 1985. № 2. С. 15-17.

4.Владимиров Ю.М. Урожайность и качество раннего картофеля в зависимости от сорта, способов проращивания и густоты посадки в условиях Волго-Вятского района: автореф. дис... канд. С.-Х. наук. М., 2001. 24 с.

5.Шабанов А.Э., Киселев А.И. Реакция новых сортов картофеля на загущение посадок // Картофель и овощи. 2019. № 11. с. 2930. https://doi.org/10.25630/pav.2019.98.67.007

6.Коршунов А.В., Федотова Л.С. Дозы, сроки и способы внесения минеральных удобрений // Достижения науки и техники АПК. 2003. С. 142-154.

7.Шабанов А.Э., Киселев А.И., Зебрин С.Н., Коровин А.С. Эффективность раздельного и комплексного применения агроприемов при выращивании картофеля// Земледелие. 2016. № 1. С. $38-40$.

8.Методика исследования по культуре картофеля / под ред. Н.С. Бацанова. М.: НИИКХ, 1967. 262с.

9.Кирюхин В.П. Методика физиолого-биохимических исследований картофеля. М.: НИИКХ, 1989. 142 с.

10.Методические указания по определению столовых качеств картофеля / под ред. С.М. Букасова. Л.: 1975. 15 с.

11.Методика определения экономической эффективности использования в сельском хозяйстве результатов научных исследований и опытно-конструкторских работ, новой техники, изобретений и рационализаторских предложений. М.: ВНИИПИ, 1983. 149c. (МСХ СССР ВАСХНИЛ).

12.Доспехов Б.А. Методика полевого опыта (с основами статистической обработки результатов исследований). М.: Агропромиздат, 1985. $336 \mathrm{c.}$

\section{Об авторах}

Киселев Александр Иванович, канд. с.-х. наук с.н.с. отдела агротехнологической оценки сортов и гибридов

Шабанов Адам Эмирсултанович, канд. с.-х. наук, зав. отделом агроэкологической оценки сортов и гибридов

Всероссийский научно-исследовательский институт картофельного хозяйства имени А.Г. Лорха. E-mail: agro-vniikh@mail.ru
1.Zhuchenko A.A. Ways of comprehensive intensification of crop production. Future of science: international yearbook. Moscow: Znanie. 1984. №17. Pp. 168-176 (In Russ.).

2.Budin K.S. For a high crop of potatoes. Leningrad: Znanie. 1981. 36 p. (In Russ.)

3.Dmitrieva S.A. Optimal terms of planting. Potato and vegetables. 1985. №2. Pp. 15-17 (In Russ.).

4.Vladimirov Yu.M. Productivity and quality of early potatoes depending on the variety, methods of germination and planting density in the conditions of the Volga-Vyatka district: abstract of diss. Cand. Agr. Sci. Moscow. 2001. 24 p. (In Russ.).

5.Shabanov A.E., Kiselev A.I. Reaction of new potato varieties to thickening of plantings. Potatoes and vegetables. 2019. №11. Pp. 29-30 (In Russ.).

6.Korshunov A.V., Fedotova L.S. Doses, terms and methods of applying mineral fertilizers. Achievements of science and technology in agriculture. 2003. Pp. 142-154 (In Russ.).

7.Shabanov A.E., Kiselev A. I., Zebrin S.N., Korovin A. S. Efficiency of separate and complex application of agricultural methods for growing potatoes. Agriculture. 2016. №1. Pp. 38-40 (In Russ.).

8.Batsanov N.S. Methods of research on potato culture. Moscow. Lorch Potato Research Institute, 1967. 262 p. (In Russ.).

9.Kiryukhin V.P. Method of physiological and biochemical research of potatoes. Moscow. Lorch Potato Research Institute. 1989. 142 p. (In Russ.).

10.Bukasov S.M. Methodological guidelines for determining the table qualities of potatoes. Leningrad. 1975. 15 p. (In Russ.). the results of scientific research and development work, new equipment, inventions and innovation proposals in agriculture. Moscow: VNIIPI. 1983. 149 p. (Ministry of agriculture of the USSR VASHNIL) (In Russ.).

12.Dospekhov B.A. Method of field experiments (with the basics of statistical processing of research results). Moscow: Agropromizdat. 1985. 336 p. (In Russ.).
11. Methodology for determining the economic efficiency of using 